\title{
A disponibilidade para as carreiras nas áreas de ciências biológicas e saúde das egressas do programa de vocação científica da fundação Oswaldo $\mathrm{Cruz}^{1}$
}

Bruna Navarone Santos bnavarone@gmail.com Universidade do Estado do Rio de Janeiro/

Fundação Oswaldo Cruz/

Escola Politécnica de Saúde Joaquim Venâncio,

Rio de Janeiro, Brasil

Ana Tereza Pinto Filipecki ana.filipecki@gmail.com Fundação Oswaldo Cruz/ Escola Politécnica de Saúde Joaquim Venâncio,

Rio de Janeiro, Brasil

Cristiane Nogueira Braga cpercini@gmail.com

Fundação Oswaldo Cruz/

Escola Politécnica de Saúde Joaquim Venâncio,

Rio de Janeiro, Brasil

Isabela Cabral Félix de Sousa isabelacabralfelix@gmail.com Fundação Oswaldo Cruz/

Escola Politécnica de Saúde Joaquim Venâncio,

Rio de Janeiro, Brasil

\section{RESUMO}

O Programa de Vocação Científica (Provoc), primeira estratégia de Iniciação Científica no Ensino Médio no Brasil, recebe jovens nos laboratórios de pesquisa da Fundação Oswaldo Cruz (Fiocruz) para participar de atividades científicas. Há uma predominância feminina nos mais de trinta anos deste programa. Isto se dá numa instituição dedicada à saúde pública brasileira que atrai mais mulheres. Foram realizadas entrevistas semiestruturadas de 2007 a 2010 com vinte e três moças e nove rapazes para conhecer mais sobre os/as egressos/as do Provoc. Neste estudo, investigamos se as trajetórias acadêmicas e profissionais dos/as egressos/as do Provoc estão relacionadas à escolaridade dos pais, favorecendo a permanência. Também analisamos se as relações de gênero influenciam as escolhas por áreas acadêmicas consideradas femininas. No final, concluímos que moças mais do que os rapazes apresentam perfis profissionais ligados às áreas de Ciências Biológicas e de Saúde.

PALAVRAS-CHAVE: Egressos. Ensino Médio. Iniciação Científica 


\section{INTRODUÇÃO}

O objetivo deste trabalho é compreender por meio do universo de trinta e duas entrevistas semiestruturadas realizadas com vinte e três moças e nove rapazes quais são os possíveis fatores favoráveis à dedicação e à permanência na graduação em áreas de Ciências Biológicas e de Saúde. Primeiro, optamos por analisar as trajetórias dos/as egressos/as levando em consideração o nível de escolaridade dos pais. Consideramos se este é um fator que pode ser associado à disponibilidade dos/as egressos/as nas áreas de Ciências Biológicas e Saúde. Em segundo lugar, perguntamos se as escolhas acadêmicas e/ou profissionais podem ser influenciadas pelas relações de gênero, visto que existem aprendizagens e profissões construídas como femininas ou masculinas.

\section{METODOLOGIA}

Foram realizadas entrevistas semiestruturadas em 2007 a 2010 com vinte e três moças e nove rapazes para conhecer mais sobre os/as egressos/as do Provoc. Nesta pesquisa, a partir da leitura das entrevistas, considerando os objetivos e as ques-tões de estudo já citadas, definiram-se unidades de registro - frases relevantes dos relatos - unidades de contexto - o contexto do qual faz parte as mensagens destes relatos - e categorias - estas abrangem elementos ou aspectos com características em comum ou que se relacionam entre si (MINAYO; 1994). As categorias foram formuladas a partir da leitura dos relatos. Investigamos o que está subjacente aos relatos destes/as jovens ao estabelecer articulações entre os dados e os refe-renciais teóricos desta pesquisa, com base nos objetivos.

Decidimos fazer a classificação de egressos/as através de uma das variáveis do contexto familiar, isto é, a escolaridade dos pais. Classificamos em duas categorias diferentes: egressos/as com ao menos um dos pais com Ensino Superior Completo e egressos/as com ambos os pais sem Ensino Superior Completo. Comparando a primeira e a segunda categoria, consideramos que os primeiros podem ter uma socialização mais familiarizada com o ambiente acadêmico por terem ao menos um dos pais como modelo a seguir, como também maior chance de apoio financeiro e /ou incentivo destes, possibilitando dar prioridade à graduação quando estudantes.

A conciliação da graduação com trabalhos ligados ou não a área de formação dos/as egressos/as também é analisada e, para tal, classificamos seus respectivos relatos em duas categorias: prioridade/oportunidade à graduação e não prioridade/oportunidade a graduação. Ou seja, a primeira categoria refere-se a relatos de egresso/a que está na graduação, tem bolsa de iniciação científica ou faz estágio e pretende só trabalhar após graduação ou pós-graduação; ou diz trabalhar junto à graduação e possui bolsa de iniciação científica ou estágio. Já a segunda categoria refere-se aos relatos que revelam sobre o/a egresso/a não ter iniciado graduação e priorizar o trabalho; ou ter de trabalhar de forma a não conseguir priorizar a graduação quando, por exemplo, relata não poder fazer iniciação científica por não poder financeiramente se manter nesta atividade e o trabalho dificultar a dedicação aos estudos. Ao considerar ambos os gêneros, perguntamo-nos se há diferenças nesta disponibilidade entre moças e rapazes. 


\section{PROVOC-FIOCRUZ DO RIO DE JANEIRO}

O Programa de Vocação Científica da Fiocruz (Provoc-Fiocruz) do Rio de Janeiro, primeira proposta formal e abrangente de Iniciação Científica na Educação Básica no Brasil, foi criado em 1986 e estabelecido na Escola Politécnica da Saúde Joaquim Venâncio (EPSJV). O êxito desta experiência no campus do Rio de Janeiro possibilitou em 1996 sua descentralização para unidades da Fiocruz nas cidades de Recife, Salvador e Belo Horizonte.

O Provoc-Fiocruz do Rio de Janeiro é coordenado por uma equipe multidisciplinar de profissionais do Laboratório de Iniciação Científica na Educação Básica (Lic-Provoc) da EPSJV, programa que busca proporcionar aos alunos/as de Ensino Médio a experiência em ambientes de pesquisa como também em desenvolvimento de projetos tecnológicos. Desta forma, oferece oportunidade de formação não formal também aos jovens ainda adolescentes. Nesse contexto, os/as estudantes do Provoc têm a possibilidade de se familiarizarem com questões relacionadas ao mundo do trabalho e à própria atividade acadêmica que abrange definição e/ou escolha profissional. Os/as alunos/as são alocados em laboratórios com ampla gama de linhas de pesquisa em sua maioria voltadas às áreas de Ciências Biológicas e Saúde.

O Provoc-Fiocruz do Rio de Janeiro durante os seus mais 30 anos de existência proporcionou aos estudantes a vivência da iniciação científica em diversos laboratórios da Fiocruz. E, dentre esses estudantes, 1322 são moças e 601 são rapazes. No total, as moças representam $68,7 \%$ dos estudantes que já ingressaram no Provoc. Estes dados revelam a predominância feminina no Provoc até hoje e também podem explicar a maior facilidade em ter contato com as egressas do que com os egressos para as entrevistas semiestruturadas deste estudo.

O presente estudo possui inspiração em dois projetos desenvolvidos no Provoc-Fiocruz. O primeiro intitulado de Vocação científica e profissão: análise da trajetória profissional de egressos do Programa de Vocação Científica (Provoc) da Fundação Oswaldo Cruz (2007-2010), trabalho que teve como um dos objetivos investigar as contribuições do Provoc a partir das vozes dos/as egressos/as. Nesta pesquisa, os/as jovens relatavam que ampliaram a sua visão de ciência e tecnologia, vivenciaram experiências que contribuíram para seu crescimento pessoal e profissional, aumentando as redes sociais (SILVESTRE; BRAGA E SOUSA, 2009).

O outro projeto de pesquisa denomina-se Gênero e iniciação científica: buscando compreender a predominância feminina no Programa de Vocação Científica (2006-2008), voltado ao estudo da visão de alunos/as de Ensino Médio do Provoc do Rio de Janeiro e de Recife sobre a predominância das moças que é característica de ambos os locais dos programas. A partir dos relatos destes/as alunos/as entrevistados/as os resultados indicam características positivas atribuídas ao sexo feminino favorecendo a maior participação das moças do Provoc: maturidade, responsabilidade, organização e paciência para participar de um processo seletivo. A Biologia está sendo vista por estes/as como área feminina do conhecimento, atraindo mais as moças (SOUSA; BRAGA; FRUTUOSO; FERREIRA E VARGAS, 2009). 


\title{
ESCOLARIDADE DOS PAIS E A DISPONIBILIDADE PARA AS CIÊNCIAS BIOLÓGICAS E SAÚDE
}

A individualidade é socialmente constituída e o habitus primário do ambiente familiar é uma primeira e profunda impressão social sobre o indivíduo (MONTAGNER; 2007). Há ainda uma grande complexidade de experiências escolares, comunitárias, culturais e sociais, vivenciadas pelos jovens. Sobre a construção do conceito de trajetória, Bourdieu (1996) nos lembra de que a história de vida:

\begin{abstract}
Ela conduz à construção da noção de trajetória como série de posições sucessivamente ocupadas por um mesmo agente (ou um mesmo grupo) num espaço que é ele próprio um devir, estando sujeito a incessantes transformações. Tentar compreender uma vida como uma série única e por si suficiente de acontecimentos sucessivos, sem outro vínculo que não a associação a um 'sujeito' cuja constância certamente não é senão aquela de um nome próprio é quase tão absurdo quanto tentar explicar a razão de um trajeto no metrô sem levar em conta a estrutura da rede. (BOURDIEU; 1996, p.189-190)
\end{abstract}

Compreendemos que as trajetórias acadêmicas e/ou profissionais destes/as egressos/as podem ser estimuladas e sustentadas pelas famílias de modo diferenciado na medida em que se espera destes/as atitudes distintas frente ao futuro, dependendo do seu nível de escolaridade dos familiares e o gênero deste/a jovem. Portanto, a família se mostra como contexto de socialização que pode contribuir para escolhas acadêmicas e/ou profissionais dos/as jovens (SPOSITO, 2004 apud PERES; ARARIPE E BRAGA, 2009). Sonnert (2009), por exemplo, em seu trabalho testa duas hipóteses para a influência dos pais na carreira de cientistas, uma denominada de papel-modelo e outra de oportunidade-estrutura. $\mathrm{Na}$ primeira hipótese, as mulheres cientistas mencionariam mais as mães por serem modelos e na segunda hipótese, citariam mais os pais de ambos os sexos com maior nível educacional do que aqueles pais com menor nível educacional. Neste estudo de Sonnert com cientistas americanos a segunda hipótese ganhou. Assim, as moças cientistas participantes se referiram mais a influência de ambos os pais do que os participantes que são rapazes cientistas. Além disto, os pais são mais mencionados do que as mães como influentes. Finalmente, o maior nível educacional dos pais de ambos os sexos parece contar tanto para os rapazes como para as moças cientistas, mas as moças cientistas mencionam também outras características importantes dois pais, como ser resiliente, trabalhador e realizador, além do nível educacional.

Entendemos assim que a influência dos pais de ambos os sexos na trajetória envolve os arranjos nas estruturas da família, educação e trabalho que marcam os/as jovens, porque estes/as se relacionam com diferentes oportunidades numa sociedade de classes em que o mercado de trabalho se encontra cada vez mais precário, exigente e excludente.

Os/as jovens podem optar tanto por postergar a inserção no mercado de trabalho para dedicação exclusiva aos estudos como por precocemente ingressar nesse mercado em atividades de menor prestígio social para sustentar a si mesmo e/ou família. Entre os/as jovens existem diferenças que vão determinar as decisões 
que são tomadas em relação a uma carreira e ao início e tipo da trajetória (PAIS, 1993 apud PERES; ARARIPE E BRAGA, 2009) que no nosso caso podem implicar numa maior disponibilidade ou não dos/as egressos/as nas áreas de Ciências Biológicas e da Saúde. Portanto, são constituintes das trajetórias dos/as egressos/as do Provoc: os espaços de socialização, tais como a família e a escola, que por sua vez influenciam as suas aspirações e expectativas por escolarização e trabalhos e suas decisões de que época ingressar no mercado de trabalho (PERES; ARARIPE E BRAGA, 2009).

Em 2014, o IBGE pesquisou alguns fatores relacionados ao desempenho dos filhos no mercado de trabalho no Brasil, por meio do Suplemento de Mobilidade Sócio-Ocupacional da Pesquisa Domiciliar por Amostra de Domicílio (PNAD). Sabese que os níveis educacionais dos pais estão relacionados à mobilidade social e ocupacional dos filhos, visto que a educação formal dos pais influencia na trajetória profissional e na renda dos filhos. Estes resultados indicam que a educação e o trabalho de pessoas ocupadas estão associados ao nível educacional dos seus próprios pais (IBGE; 2016).

Além do aumento das condições econômicas das famílias brasileiras, relacionadas ao seu nível de escolaridade cada vez maior, entende-se que a democratização do acesso ao ensino superior tem permitido jovens seguirem estudando ao invés de somente trabalharem. Esta democratização foi estimulada pelo governo do Partido dos Trabalhadores de 2002 até 2016 por políticas públicas de interiorização de universidades públicas, aumento das reservas de vagas nas instituições públicas aos alunos portadores de deficiência, egressos de escola pública, com baixa renda familiar, etnias específicas, etc., como também o aumento do financiamento estudantil reembolsável (Fundo de Financiamento Estudantil - FIES) e não reembolsável (Programa Universidade para Todos ProUni), direcionado aos alunos das instituições privadas (IBGE; 2016).

Pode-se perceber que a ideia de trajetória dos jovens é relevante para compreender como se estabelece a noção de projeto que pode ser influente nas trajetórias acadêmicas e/ou profissionais dos/as jovens: noção a qual exige cálculo, planejamento, noção de riscos e perdas, a ideia de campo de possibilidades, que diz respeito ao sistema de relevâncias e motivação do sujeito que afetam a justificativa e o porquê das ações, e traduz-se no seu sistema de motivações (SCHUTZ, 1971; VELHO, 1997 apud PERES; ARARIPE E BRAGA, 2009).

\section{GÊNERO E A DISPONIBILIDADE PARA AS CIÊNCIAS BIOLÓGICAS E DE SAÚDE}

Considerando a noção de trajetória acima exposta, procuramos analisar se esta está imbricada com a questão de "gênero". Consideramos a perspectiva de gênero (SCOTT; 1995) para compreender outros fatores sociais que podem ser relevantes para as preferências acadêmicas e/ou profissionais destes/as egressos/. Natalie Davis (1976) também faz referência à concepção de gênero que busca tratar da importância de estudar a condição da mulher indissociavelmente em relação ao homem:

Penso que nós deveríamos nos interessar pela história dos homens e das mulheres, que nós não deveríamos estar trabalhando somente sobre o sexo sujeitado, assim como qualquer um historiador de classe não fixa seu olhar apenas 
sobre os camponeses. Nosso objetivo é entender o valor dos sexos, isto é, dos grupos de gênero no passado histórico. Nosso objetivo é descobrir o leque dos papéis sexuais e do simbolismo sexual nas diferentes sociedades e períodos, é encontrar que sentido e como eles funcionavam para manter a ordem social ou para mudá-la (DAVIS; 1976, p.90, tradução nossa).

Considera-se "gênero" como aspecto relacional das definições normativas de feminilidade e, portanto, a necessidade de compreender estas definições como constituídas na relação entre mulheres e homens. E, segundo essa visão, ambos são definidos em termos recíprocos e não se poderia compreender qualquer um por meio de um estudo inteiramente separado, visão a qual nós apoiamos com a intenção de investigar e compreender a questão da disponibilidade de egressas e egressos. Compreender as escolhas acadêmicas e/ou profissionais como relacional implica a tentativa de analisar a forma pela qual opera essa oposição binária, entre mulheres e homens, e sua construção hierárquica que se sustenta como determinada pela natureza: universal e imutável.

Formiga (2006) descreve o consenso da cultura ocidental atual sobre as mulheres serem mais aptas às carreiras que exigem mais habilidades para relacionamento interpessoais, expressas nas emoções socialmente consideradas como femininas. Segundo Formiga (2006), de acordo com tal consenso, às mulheres cabe a expressão de suas emoções como a alegria e tristeza e aos homens cabe a expressão das emoções como a raiva. Estas emoções refletem processos geralmente considerados subjetivos e naturais; no entanto, são fundadas em estereótipos e papéis de gênero tradicionais naturalizados. Estes são capazes de condicionar comportamentos e habilidades para que sejam condizentes a uma concepção e conduta sobre o papel ideal de gênero, que mulheres e homens são socializados a internalizar.

Compreendemos as representações dos papéis feminino e masculino não como universais, e sim contextuais, principalmente quando se trata da diferença entre mulheres e homens, pois, socialmente, algumas condutas guiam os indivíduos contribuindo para que se adotem características psicológicas e comportamentais a respeito de estereótipos ligados a gênero, destacando diferenças: ao homem atribui-se competência e racionalidade e às mulheres associa-se calor emocional, afetividade e sensibilidade (FORMIGA; 2006).

Estes estereótipos podem condicionar as mulheres a apenas escolherem carreiras tipicamente femininas, como as de: Educação, Letras, Humanidades, Saúde e Secretariado (MELLO; 1975), profissões comumente vistas como atividades próximas aos papéis de mãe e esposa, enquanto os rapazes tendem a escolher mais por áreas como Ciências (GUEDES; 2008). Esta hierarquização quanto ao gênero tem legitimado diferentes habilidades e comportamentos das pessoas em determinadas áreas e profissões. As expectativas operam de forma a motivar estes indivíduos a escolherem áreas e profissões consideradas mais adequadas ao seu gênero (BARROSO; 1977).

A trajetória do indivíduo é afetada pelas expectativas daqueles com quem convive. Portanto, jovens podem ser levados a desenvolver interesses, disposições e habilidades consideradas apropriadas dependendo do seu gênero. Por exemplo, algumas oportunidades para desenvolver potencialidades para uma determinada área podem ser negadas, com base no pressuposto de que requerem habilidades 
encontradas essencialmente nos indivíduos de outro sexo. (BARROSO; 1977). Assim, a distribuição de mulheres e homens pelas diferentes carreiras continua a ser muito caracterizada por gênero, persistindo a crença de que existem profissões femininas e masculinas.

Saboya (2013) verifica que a baixa representação das mulheres em comparação aos homens nas áreas de Ciência e Tecnologia está relacionada ao pressuposto das mulheres não terem habilidades nem talentos necessários. Este preconceito enfatiza que o gênero masculino é mais adequado às práticas desta carreira pela sua objetividade e racionalidade.

Diante desta questão de haver profissões mais socialmente receptivas às características culturalmente femininas, a expressividade emocional por um lado pode ser vista como uma melhor forma de lidar com relacionamentos interpessoais, sustentada pela ideia da inteligência emocional. Por outro lado, ser muito emotivo tem sido retratado de modo negativo e associando-se ao gênero feminino, num discurso de maior vulnerabilidade das mulheres em comparação aos homens quando diz respeito à atuação das mulheres em áreas tipicamente masculinas, como as Engenharias (BARRETO; 2014).

\section{RESULTADOS}

Optamos por diferenciar os/as egressos/as naqueles que têm ao menos um dos pais com Ensino Superior Completo daqueles/as que têm ambos os pais sem Ensino Superior Completo. Considerando o universo de vinte e três moças, dezoito egressas têm ao menos um dos pais com Ensino Superior Completo. Destas egressas, três trabalham concomitante a graduação: duas trabalham enquanto cursam Biologia, uma como vendedora de cosméticos e a outra como recreadora em festas, e ainda outra egressa enquanto cursa Medicina já trabalhou numa loja de roupas. Estas dezoito egressas relatam prioridade/oportunidade à graduação dedicar-se à graduação e só trabalhar após esta ou depois da futura pósgraduação; ou trabalhar junto à graduação, ao mesmo tempo em que se dedicam à mesma com bolsa de iniciação científica ou estágio - e destas, doze estavam em áreas de Ciências Biológicas e Saúde (cinco em Biologia; uma em Enfermagem; duas em Farmácia; quatro em Medicina). Levando em conta as cinco egressas cujos pais não têm Ensino Superior Completo, uma destas trabalha concomitantemente à graduação em Biologia, numa loja de roupas, priorizando o trabalho porque relata não ter feito um estágio devido à dedicação neste emprego. Relata dificuldade para conciliar o trabalho com a graduação e já teve que pedir atestados médico para faltar ao trabalho e poder estudar. Também diz que trabalha como professora de Ciências no Ensino Fundamental. As outras quatro egressas relatam prioridade/oportunidade à graduação, e uma destas atua em área da Saúde, na Medicina.

Já no caso dos nove rapazes, cinco egressos têm ao menos um dos pais com Ensino Superior Completo. Destes, um relata estar trabalhado junto à graduação de Biologia como sócio numa empresa de assessoria pedagógica, onde dá aula e faz serviços administrativos para as escolas clientes. Estes cinco egressos que estão em área de Ciências Biológicas e Saúde (dois em Biologia; dois em Farmácia; um em Medicina) relatam prioridade/oportunidade à graduação. Enquanto quatro 
egressos têm pais sem Ensino Superior Completo. Um destes já havia trabalhado como administrador de cartão de credito, durante o seu segundo ano no prévestibular, antes de ingressar no curso de Medicina. Destes egressos, outro egresso não havia iniciado a graduação, priorizando o trabalho. Este já havia trabalhado na área de telemarketing, informática, Militar e atua como operador de tráfego terceirizado. Também diz que não está contente com a sua escolha profissional, pois o seu objetivo é cursar Biologia. Ainda, três egressos relatam prioridade/oportunidade à graduação e dois destes estão em área de Ciência Biológica e Saúde (um em Biologia e outro em Medicina).

Notamos que dentro do universo de vinte e três egressas, a maioria das egressas com ao menos um dos pais com Ensino Superior Completo como as com ambos os pais sem Ensino Superior Completo relatam prioridade/oportunidade à graduação nas áreas de Ciências Biológicas e de Saúde, exceto uma egressa que relata não ter conseguido um estágio na sua graduação em Biologia por ter de trabalhar, priorizando o trabalho. Já no caso dos egressos, dentro do universo de nove respondentes, há diferenças entre os relatos dos alunos no que diz respeito à prioridade/oportunidade à graduação em Ciências Biológicas e Saúde. Assim como as moças da categoria prioridade/oportunidade à graduação, os cinco egressos com ao menos um dos pais com Ensino Superior Completo relatam prioridade/oportunidade à graduação e a maioria está em áreas de Ciências Biológicas e Saúde. Embora, dentre os outros quatro egressos com ambos os pais sem Ensino Superior Completo, três tenham relatado prioridade/oportunidade à graduação e dois destes na área de Ciências Biológicas ou em Saúde, os relatos sobre preocupação e necessidade em ingressar imediatamente no mercado de trabalho foram predominantes neste último grupo e houve o único caso de um egresso não ter ingressado na graduação, priorizando o trabalho.

Podemos melhor compreender a maior disponibilidade das egressas para a academia (independentemente da escolaridade dos pais) diante da disponibilidade dos egressos mediante seus respectivos relatos. Para ilustrar, apresentamos as respostas de quatro egressos/as a seguinte questão: Você considera ter adquirido conhecimentos úteis participando no Provoc? Em caso positivo, poderia dar exemplo(s)?

"Sim, aprendi a ser responsável. A vivência no laboratório foi muito importante. Aprendi a redigir trabalhos científicos, comparando com os colegas da graduação que não tiveram esta experiência". Feminino, 26 anos, graduada em Biologia.

"Sim, a interação entre as pessoas no trabalho, vir sozinha de casa, a responsabilidade para os experimentos, além dos conhecimentos teóricos". Feminino, 21 anos, graduanda em Medicina.

"Sim, primeiro pelo amadurecimento, pois entrei no programa com 15, 16 anos em um ambiente de pesquisa como o da Fiocruz antes da Faculdade, que é uma experiência ímpar, quanto mais aprender a fazer pesquisa, projetos, préprojetos, etc.". Masculino, 23 anos, graduando em Biologia.

"Com certeza, na questão do aprendizado no laboratório. Na própria atividade que exerço atualmente, a atividade de Farmácia, descobri no Provoc. Todos os conceitos que aprendi e que ajudaram a direcionar minhas escolhas. A 
apresentação de trabalhos, já que eu era tímido. O pessoal que angariei na experiência do Provoc, meu desenvolvimento pessoal". Masculino, 22 anos, graduando em Farmácia.

Percebemos diante dos relatos dos/as egressos/as em áreas das Ciências Biológicas e Saúde que são frequentes algumas características nos termos: amadurecimento, responsabilidade, desenvolvimento pessoal, relacionamento interpessoal, características geralmente atribuídas a perfis profissionais femininos: por exemplo, perfis profissionais socialmente desejáveis para as áreas de Ciências Biológicas e de Saúde que associamos mais ao gênero feminino, no sentido de tais áreas comumente serem, tanto no magistério e na saúde, voltadas ao contato com o público e ao cuidado. Podemos refletir a questão de supostas profissões adequadas às mulheres para investigar as trajetórias acadêmicas e/ou profissionais das egressas: às mulheres parece ser mais adequado ingressar em áreas voltadas a empregos que tenham o contato com o público e que enfatize os relacionamentos interpessoais, como no caso do magistério, saúde, serviços e entretenimento. Daí existe certa cobrança social de estarem alegres, com bom humor e dispostas a resolverem problemas de relação interpessoal, pois caso não aconteça forma-se uma atmosfera de inadequação ao papel feminino esperado (FORMIGA; 2006).

\section{CONSIDERAÇÕES FINAIS}

A maioria dos/as egressos/as deste estudo está em áreas de Ciências Biológicas e da Saúde. O que distingue as moças e os rapazes estudados é que as primeiras priorizam mais a graduação nestas áreas, mesmo tendo o modelo familiar onde os pais não têm Ensino Superior Completo e algumas fazendo trabalhos esporadicamente não vinculados à formação acadêmica. Não podemos afirmar que a escolaridade dos pais promove uma disponibilidade para as áreas das Ciências Biológicas e da Saúde e, sim, para fazer algum curso de graduação. Isto corrobora o estudo de Sonnert (2009) de que o maior nível educacional dos pais é importante influência para a trajetória científica. Os diferentes níveis de escolaridade dos pais podem auxiliar a melhor compreender as diferentes trajetórias dos/as egressos/as.

As características relatadas pelos/as egressos/ as como "amadurecimento", "responsabilidade", "desenvolvimento pessoal", "relacionamento interpessoal" geralmente caracterizadas como femininas são relacionadas com características favoráveis a dedicação e a permanência das egressas, conforme outro estudo já apontado (SOUSA et al, 2008). Parece que as relações de gênero influenciam a escolha de moças por áreas acadêmicas que já são consideradas femininas, como as de Biologia e da Saúde. Assim, podemos supor que há uma relação direta entre buscar uma graduação em áreas consideradas femininas.

No entanto, acreditamos ser fundamental para futuras análises fazer mais entrevistas semiestruturadas com egressos/as, para fazer uma análise mais balanceada e comparar as trajetórias de moças e rapazes. Então, temos como questões norteadoras para aprofundar a análise da diferença de disponibilidade dos/as egressos/as: 
- De que maneira as emoções orientam as escolhas acadêmicas e profissionais das moças e rapazes?

- Os níveis de formação acadêmica dos pais são mais influentes para os rapazes do que para as moças?

- As moças não vislumbram a possibilidade de trabalhar cedo e se dedicam mais aos estudos por falta de mercado do trabalho? 


\title{
They have made (and are) part of the history of science and technology and are inventors!
}

\begin{abstract}
The Scientific Initiation Program (Provoc), the first strategy for Scientific Initiation during High School Education in Brazil, receives young students in the research laboratories of the Oswald Cruz Foundation (Fiocruz) to pursue scientific activities. There is a female predominance in the thirty years of this program. This occurs in an institution dedicated to Brazilian public health attracting more women. Semi-structured interviews were carried out from 2007 to 2010 with twenty-three girls and nine boys to know more about the trajectories of Provoc's alumni. In this study, we investigated whether the academic and professional choices and trajectories of the Provoc's students are related to the parents' schooling, favoring their permanence. We also analyzed whether gender relations influence these choices for academic fields considered feminine. Finally, we concluded that more young women than young men had professional profiles related to Biological and Health Sciences.
\end{abstract}

KEYWORDS: Alumni. High School. Scientific Initiation.

\section{La disponibilidad para las carreras en las áreas de ciencias biológicas y salud de las egresas del programa de vocación científica de la Fundação Oswaldo Cruz}

\begin{abstract}
RESUMEN
El Programa de Vocación Científica (Provoc), primera estrategia de Iniciación Científica en la Enseñanza Media en Brasil, recibe jóvenes en los laboratorios de investigación de la Fundación Oswaldo Cruz (Fiocruz) para participar en actividades científicas. Hay un predominio femenino en los más de treinta años de este programa. Esto se da en una institución dedicada a la salud pública brasileña que atrae a más mujeres. Se realizaron entrevistas semiestructuradas de 2007 a 2010 con veintitrés mozas y nueve muchachos para conocer más sobre los/las graduados/as del Provoc. En este estudio, investigamos si las trayectorias académicas y profesionales de los egresados del Provoc están relacionadas a la escolaridad de los padres, favoreciendo la permanencia. También analizamos si las relaciones de género influencian las elecciones por áreas académicas consideradas femeninas. Al final, concluimos que las jóvenes más que los chicos presentan perfiles profesionales relacionados con las áreas de Ciencias Biológicas y de Salud.
\end{abstract}

PALABRAS CLAVE: Los graduados. Enseñanza Media. Iniciación Científica 


\section{NOTAS}

${ }^{1}$ O presente trabalho foi realizado com o apoio do Conselho Nacional de Desenvolvimento Científico e Tecnológico - CNPq - Brasil

\section{REFERÊNCIAS}

BARRETO, Andreia. A mulher no ensino superior: Distribuição e representatividade. Cadernos do GEA, n. 6, 2014.

BARROSO, Carmen Lucia M. Diferenças sexuais. Cadernos de Pesquisa, n. 21, p. 47-60, 1977.

BOURDIEU, Pierre. A ilusão biográfica. In: FERREIRA, Marieta de Moraes, AMADO, Janaina. Usos e abusos da História Oral. Rio de Janeiro: Ed. da FGV, 1996, p.183191.

DAVIS, Natalie Zemon. "Women's History" in transition: the European case. Feminist studies, v. 3, n. 3/4, p. 83-103, 1976.

FORMIGA, Nilton Soares. Diferença de gênero nos antecedentes das emoções de raiva, alegria e tristeza. Revista científica eletrônica de Psicologia, 3:1-16, 2006. Disponível em:

<http://www.faef.revista.inf.br/imagens_arquivos/arquivos_destaque/kBFQM9D 3AxQwEhU_2013-4-30-16-45-34.pdf >>. Acesso em: 15 abr. 2016.

GUEDES, Moema de Castro. A presença feminina nos cursos universitários e nas pós-graduações: desconstruindo a ideia da universidade como espaço masculino. Hist. Cienc. Saúde Manguinhos, p. 117-132, 2008.

INSITUTO BRASILEIRO DE GEOGRAFIA, ESTATÍSTICA. Coordenação de Trabalho e Rendimento. Mobilidade Sócio-Ocupacional. Rio de Janeiro, IBGE, 2016.

Coordenação de População e Indicadores Sociais. Síntese de indicadores sociais: uma análise das condições de vida da população brasileira. Rio de Janeiro, IBGE, 2016.

MINAYO, Maria Cecília de Souza. (org.). Pesquisa social: teoria, método e criatividade. 7ạ ed. Petrópolis:Vozes,1994.

MONTAGNER, Miguel Ângelo. Trajetórias e biografias: notas para uma análise bourdieusiana. Sociologias, 9 (17):240-264, 2007. Disponível em: <http://www.scielo.br/pdf/soc/n17/a10n17.pdf> Acesso em: 05 abr.2016.

MELLO, Guiomar Namo de. Os estereótipos sexuais na escola. Cadernos de pesquisa, n. 15, p. 141-144, 1975. 
SILVESTRE, Viviane de Souza; BRAGA, Cristiane Nogueira\& SOUSA, Isabela Cabral Félix de. Treinamento científico no Ensino Médio: análise da visão de egressos do Programa de Vocação Científica da Fundação Oswaldo Cruz. In: Anais eletrônicos dossiê Encontro Nacional de Pesquisa em Educação em Ciências. 8. Florianópolis, 2009. Disponível

em:<http://posgrad.fae.ufmg.br/posgrad/viienpec/pdfs/1672.pdf>. Acesso em: 05 abr.2016.

SONNERT, Gerhard. Parents who influence their children to become scientists. Social Studies of Science, 39 (6): 927-941, 2009.

PERES, Simone Ouvinha; ARARIPE, Cristina\& BRAGA, Cristiane Nogueira. Estudo das trajetórias de jovens de camada popular inseridos no Provoc/Fiocruz.In: Anais eletrônicos do XIV Congresso de Sociologia. 14. Rio de Janeiro, 2009. Disponível em:

$<$ http://www.sbsociologia.com.br/portal/index.php?option=com_docman\&task= doc_download\&gid=3084\&ltemid=171>. Acesso em: 04 abr.2016.

SABOYA, Maria Clara Lopes. Relações de gênero, ciência e tecnologia: uma revisão da bibliografia nacional e internacional. Educação, Gestão e Sociedade, v. 3, n. 12, p. 1-26, 2013

SCOTT, Joan. Wallach. Gênero: uma categoria útil de análise histórica. Educação \& Realidade, 20 (2): 71-99, 1995. Disponível

em:<https://repositorio.ufsc.br/bitstream/handle/123456789/1210/scott_gende r2.pdf?sequence=1>. Acesso em: 05 abr. 2016.

SOUSA, Isabela Cabral Félix de; BRAGA, Cristiane Nogueira; FRUTUOSO, Telma de Mello \&VARGAS, Diego da Silva. The female predominance of a vocational and scientific education programme for High School Students in Rio de Janeiro and Recife, Brazil. Convergence 41: 83-97, 2008.

SOUZA, Maria Luiza de Mello e. Reflexões sobre um Programa de Iniciação Científica para o Ensino Médio. In: Anais eletrônicos do V Encontro Nacional de Pesquisa em Educação em Ciências. 5, Bauru, 2005. Disponível em: <http://www.nutes.ufrj.br/abrapec/venpec/conteudo/artigos/3/pdf/p204.pdf>. Acesso em: 02 abr. 2016.

Recebido: 23 dez. 2017

Aprovado: 04 jun. 2018

Como citar:

SANTOS, Bruna Navarone; FILIPECKI, Ana Tereza Pinto; BRAGA, Cristiane Nogueira; SOUSA, Isabela Cabral Félix de. A

disponibilidade para as carreiras nas áreas de ciências biológicas e saúde das egressas do programa de vocação

científica da fundação Oswaldo Cruz. Cad. Gên. Tecnol., Curitiba, v.11, n. 37, p. 27-39, jan./jun. 2018.

Correspondência:

Bruna Navarone Santos. Fundação Oswaldo Cruz, Escola Politécnica de Saúde Joaquim Venâncio., Avenida Brasil 4365, Manguinhos, 21045-900 - Rio de Janeiro, RJ - Brasil

Direito autoral:

Este artigo está licenciado sob os termos da Licença Creative Commons-Atribuição 4.0 Internacional. 